\title{
WILEY-VCH
}

DOI: $10.1002 /(($ please add manuscript number $))$

Article type: Communication

\section{Light-Triggered Inactivation of Enzymes with Photothermal Nanoheaters}

Sebastian A. Thompson, Sureyya Paterson, Marwa M. M. Azab, Alastair W. Wark, and Roberto de la Rica.*

S. A. Thompson, S. Paterson, M. M. M. Azab, A. W. Wark, R. de la Rica

WestCHEM, Department of Pure and Applied Chemistry, University of Strathclyde,

Technology and Innovation Centre, 99 George Street, Glasgow, G1 1RD, Scotland, UK

E-mail: Roberto.delarica@gmail.com

S. A. Thompson

${ }^{\mathrm{b}}$ Department of Chemistry and Biochemistry, Hunter College - City University of New York, New York 10065, USA

Keywords: Gold, Nanorods, Hyperthermia, Glucose Oxidase, Horseradish Peroxidase 


\section{WILEY-VCH}

\section{ABSTRACT}

Enzymes are crucial for the cell metabolism and in industrial applications such as the manufacture of biosensors and medicines. A method for inactivating enzymes non-invasively and on demand could reveal the role of a biocatalyst in a particular cell function and enable fine-tuning the therapeutic dose of enzyme-based drugs. In this manuscript we introduce a universal method for inactivating enzymes with light. It consists of attaching the enzymes to photothermal nanoheaters (gold nanorods). Upon irradiation with light resonant with their LSPR the plasmonic nanoparticles generate heat, which denatures the enzymes. The resulting increase in temperature is highest in the vicinity of the nanoheaters, which allows the localized inactivation of nanorod-bound enzymes without damaging other proteins or cell membranes present in the same solution. Here we demonstrate this concept by selectively turning off an enzyme cascade via the selective inactivation of one of its components. We also prove that the target enzyme can be inactivated without unduly damaging cells under controlled irradiation conditions. The results shown here pave the way for using the proposed methodology to discern the role of target enzymes in intracellular signaling pathways. 


\section{WILEY-VCH}

Enzymes are biological catalysts involved in crucial cellular processes such as signaling pathways, DNA replication, and protein expression. In biotechnology, enzymes are used for manufacturing biosensors, ${ }^{[1]}$ medicines, ${ }^{[2]}$ fuels ${ }^{[3]}$ and foodstuffs. ${ }^{[4]}$ A methodology for inactivating a target enzyme on demand could be useful for discerning the role of the biocatalyst in a particular cell function. ${ }^{[5]}$ A light-triggered inactivation mechanism would be ideal for these applications since it would enable turning off the enzyme activity noninvasively and on demand. Current methods for controlling the activity of enzymes with light require the synthesis of photoresponsive enzyme substrates, i.e. a molecule that changes its conformation upon irradiation at a particular wavelength. ${ }^{[6]}$ While this approach allows a fine control over the activity of a given enzyme, it can only be applied to those enzymes whose substrate can be synthesized in a laboratory. Furthermore, enzymes show exquisite specificity for the conversion of a particular substrate. This means that different lightresponsive molecules must be synthesized for each specific enzyme, which is very timeconsuming. Moreover, supplying synthetic substrates may be cumbersome in intracellular or in vivo studies, in which the photoresponsive molecules may need to permeate cell membranes and compete with naturally occurring substrates in order to inactivate the enzymes. In this context it would be highly desirable to find a generic methodology that allowed inactivating any target enzyme remotely regardless of its substrate specificity and in different biological scenarios, such as in the presence of other enzymes or in close proximity to cells.

Here we introduce a universal method for inactivating target enzymes on demand with light. The method consists of attaching the enzyme to photothermal nanoheaters, for example to gold nanorods. The nanoheaters generate plasmonic heat when irradiated with a laser resonant with their localized surface plasmon resonance (LSPR). ${ }^{[7-9]}$ The subsequent increase in temperature is the highest in the vicinity of the nanorods, ${ }^{[10,11]}$ where the enzymes are located. 


\section{WILEY-VCH}

Since the nanorod-bound enzymes are subjected to high temperatures they denature, which leads to their inactivation. With this method, it is possible to selectively inactivate the enzymes attached to the nanorods without significantly damaging other proteins or cells in the same solution, which are not subject to such high temperatures. With the exception of a small family of thermostable enzymes found in rare thermophile organisms, hyperthermia always leads to enzyme denaturation with a concomitant reduction of biocatalytic activity. This makes the proposed method a universal approach for inactivating enzymes via local generation of plasmonic heat.

Figure la shows a schematic representation of the design of the photothermal nanoheathers used here to inactivate enzymes. Gold nanorods resonant at ca. $785 \mathrm{~nm}$ were produced with a well-established seeded growth method (Figure S1 in the Supporting Information). ${ }^{[12]}$ Nanorods resonant in the near-infrared (NIR) were used because in this optical window biological components absorb less light, which allows the nanorods to be excited without damaging biomolecules with the incident laser. ${ }^{[13]}$ The CTAB surfactants surrounding the nanorods were substituted by thiolated polyethylene glycol (PEG) molecules ending in carboxylate moieties. The thiol groups anchor the PEG molecules to the surface of the nanorods. The hydrophilic PEG molecules prevent the aggregation of the nanorods in biological buffers and during bioconjugation reactions, while the carboxylate groups enable the attachment of biomolecules with covalent chemistries. Different enzymes may bind to nanorods to a different extent when using covalent chemistries, and there is a risk of inactivating enzymes as a result of the bioconjugation reactions. ${ }^{[14]}$ To avoid this, enzymes were first modified with biotin and subsequently bound to the nanorods by means of avidinbiotin interactions. Avidin was covalently attached to the PEG ligands via amidation in the presence of EDC and sulfo-NHS (see experimental section and Figure S2 in the Supporting Information). It should be noted that avidin is highly thermally stable, especially when bound 


\section{WILEY-VCH}

to biotin (its denaturation temperature changes from 83 to $117^{\mathrm{O}} \mathrm{C}$ ), ${ }^{[15]}$ and therefore it is a suitable linker for studying the inactivation of enzymes triggered by hyperthermia. Two different enzymes were biotinylated: horseradish peroxidase (HRP) and glucose oxidase (GOx). HRP generates colored molecules (oxidized TMB (3,3',5,5'-tetramethylbenzidine)) in the presence of hydrogen peroxide. ${ }^{[1]}$ GOx transforms glucose into gluconic acid and hydrogen peroxide. ${ }^{[16]}$ When combined, the enzymes work as a cascade in which the product of an enzymatic reaction (hydrogen peroxide generated by GOx) is used by the other enzyme to generate a given product (colored molecules of by HRP) (Figure 1b). ${ }^{[17]}$ Enzyme activity can be measured colorimetrically with the method detailed in the Experimental Section (Supporting Information). Solutions were illuminated with a partially focused continuous wave $(\mathrm{CW})$ laser $(785 \mathrm{~nm}, 235 \mathrm{~mW}$ at the point of incidence) in order to generate plasmonic heat.

Figure 2a shows the decrease in enzyme activity measured in a solution containing nanorods modified with HRP after irradiating the samples for different times. The samples consisted in $20 \mu \mathrm{L}$ of HRP-modified nanorods with an optical density at $785 \mathrm{~nm}$ of ca 10 (ca. $2 \mathrm{nM}),{ }^{[18]}$ which was the minimum concentration of nanoheaters that enabled detecting the HRP activity with confidence. After shining the laser, the remaining HRP activity was calculated with respect to a non-irradiated sample. In these experiments, the enzyme becomes totally inactive after irradiation for $90 \mathrm{~s}$ or longer (see also Figure S5 online). It has been proposed that nanoparticle-mediated hyperthermia is intimately related to the concentration of nanoheaters as well as to the laser power. ${ }^{[19]}$ High nanoparticle concentrations and low laser powers result in an increase in the temperature of the bulk of the solution. ${ }^{[19]}$ On the contrary low nanoparticle concentrations and high laser power values favor a local increase in the temperature around the nanoheaters. ${ }^{[19]}$ The following experiments were performed in order to discern whether the inactivation of HRP in Figure 2a is triggered by a local change in 


\section{WILEY-VCH}

temperature or by a change in the temperature of the bulk of the solution. First the solution temperature was measured by irradiating the nanorods with a laser while measuring the temperature with a thermocouple away from the beam path (Figure $2 b$ ). Then the temperature of the enzyme solution was increased with a heating block to the different final values shown in Figure $2 b$. The temperature of the solution was measured in a neighboring tube treated in exactly the same conditions as the solution containing enzymes. This was done to avoid contaminating the enzyme solution with the thermometer. Each sample was left at the final given temperature for at least 2 minutes, which is longer than the laser irradiation time. In Figure $2 \mathrm{c}$ raising the temperature of the solution has almost no effect on the HRP activity compared to the photothermal experiments in Figure 2a, in agreement with previous studies showing that HRP activity does not change significantly when incubated at temperatures as high as 65 degrees for a few minutes. ${ }^{[20]}$ This demonstrates that the inactivation of HRP in Figure 2a was originated by a local change in temperature, since the resulting variations of the temperature of the bulk of the solution cannot inactivate the enzymes to the same extent. These experiments pave the way for inactivating enzymes bound to nanoheaters selectively in the presence of other proteins free in the solution. Since the largest variations in temperature are registered close to the nanorods within the laser beam path, only those proteins diffusing nearby will be susceptible to hyperthermia, and only for a short period of time. Conversely, the target enzyme is concentrated around the nanorods and unable to diffuse away from the region where the increase in temperature is the highest. ${ }^{[11]}$

Next we designed a model enzyme cascade containing GOx and HRP (Figure 1b) and tested whether it is possible to control the activity of the cascade by selectively inactivating one of its constituent enzymes with the proposed methodology. In these experiments GOx is bound to the nanorods while HRP is free in solution. The end product of the cascade is a bluecolored molecule generated by HRP only when both enzymes are active. In Figure 3a, when 


\section{WILEY-VCH}

the solution containing HRP and nanorod-bound GOx was irradiated with the $785 \mathrm{~nm}$ laser, the enzyme activity resulting from the cascade rapidly decreased as the irradiation time increased. To demonstrate that the observed decrease in activity is originated by the inactivation of GOx with local hyperthermia and not by the denaturation of HRP, the irradiation experiments were performed in exactly the same conditions but the HRP activity was measured after adding hydrogen peroxide peroxide instead of generating this cofactor in situ via the oxidation of glucose by GOx. Under this condition the measured HRP activity is independent from the GOx activity. Figure $3 \mathrm{~b}$ shows that in this case the HRP activity does not change significantly, and therefore the decrease in activity observed in Figure $3 \mathrm{a}$ is originated by the selective inactivation of nanorod-bound GOx and not by the denaturation of HRP. It should be noted that, in Figure 3b, irradiating the sample for $90 \mathrm{~s}$ has little effect on the HRP molecules free in the solution, whereas in Figure 2a it totally inactivated the nanorod-bound enzymes. Therefore these results corroborate our previous outcomes that, under controlled irradiation conditions, only nanorod-bound enzymes are inactivated with the proposed methodology.

Photothermal nanoheaters have been traditionally used for killing cancer cells in photothermal therapy. ${ }^{[21-23]}$ Usually this requires irradiating the cells for relatively long periods of time. We hypothesized that enzymes could be inactivated without unduly damaging cells when the nanorods are irradiated for short periods of time. To explore this idea, GOx-coated nanorods were added to cell culture plates containing Chinese hamster ovary $(\mathrm{CHO})$ cells and were irradiated for different times. In Figure S3 (Supporting Information), the GOx activity in samples containing GOx-modified nanorods and cells decreased as the irradiation time increased, in line with the results shown in Figure 3a. Any damage to the cell membrane resulting from photothermal effects in these experiments was evaluated by adding ethidium bromide to the culture plates. This compound only becomes fluorescent upon interacting with 


\section{WILEY-VCH}

the nuclei of cells whose membrane has been damaged. ${ }^{[9]}$ In Figs. $4 \mathrm{a}-\mathrm{d}$ when $\mathrm{CHO}$ cells were irradiated for $15,30,60$ or $90 \mathrm{~s}$ no damage to the cell membrane was registered. These experiments demonstrate that it is possible to inactivate GOx without damaging the membrane of $\mathrm{CHO}$ cells. In Figure $4 \mathrm{e}$ all the cells show clearly fluorescent nuclei because they were irradiated with the same laser and nanorod concentration for $600 \mathrm{~s}$. Cells that were irradiated in the absence of nanorods for $600 \mathrm{~s}$ were unaffected by the lasers, which confirms that the cells in Figure 4e were damaged by photothermal effects (Fig. S4 in the Supporting Information). These experiments are promising for using the proposed method for selectively inactivating enzymes without killing cells when controlling the laser irradiation time.

In conclusion we have demonstrated that enzymes can be inactivated via local generation of plasmonic heat when bound to photothermal nanoheaters. Inactivation of nanoparticle-bound enzymes happens much faster than the inactivation of free enzymes or the damaging of cell membranes, which enables the inactivation of target enzymes selectively. We have also demonstrated that it is possible to control the overall activity of an enzyme cascade by selectively inactivating one of its components with the proposed methodology. In biotechnology enzyme cascades are used in the production of biosensors ${ }^{[24]}$ and biofuels. ${ }^{[3]}$ In cells, they are involved in signaling pathways and the production of energy. ${ }^{[25]}$ We envisage that the proposed methodology could be used to selectively shut down intracellular cascades by targeting one of its constituent enzymes. For example nanorods decorated with antibodies could collect and bind the target enzyme in the vicinity of the nanoheaters selectively, where they could be subsequently inactivated with plasmonic heat. Short radiation pulses could be applied to inactivate the enzyme without unduly damaging the cells. It should be noted that hyperthermia could be used to denature proteins other than enzymes, for example membrane receptors and structural proteins. Therefore the proposed method could also be used to study relationships between the changes in the structure of proteins and their function in situ. 


\section{WILEY-VCH}

\section{Experimental Section}

The experimental section is available in the Supporting Information online.

\section{Supporting Information}

Supporting Information is available from the Wiley Online Library or from the author.

\section{Acknowledgements}

S. A. T. acknowledges a PEER/PECRE travel grant from WestCHEM. R. R. acknowledges a Tom West Analytical Fellowship from the Analytical Chemistry Trust Fund.

Received: ((will be filled in by the editorial staff))

Revised: ((will be filled in by the editorial staff)) Published online: ((will be filled in by the editorial staff))

[1] E. F. O’Connor, S. Paterson, R. de la Rica, Anal. Bioanal. Chem. 2016, 408, 3389.

[2] N. H. Tsao, E. A. H. Hall, Langmuir 2016, 32, 6534.

[3] M. Gunnoo, P. A. Cazade, A. Galera-Prat, M. A. Nash, M. Czjzek, M. Cieplak, B. Alvarez, M. Aguilar, A. Karpol, H. Gaub, M. Carrion-Vazquez, E. A. Bayer, D. Thompson, Adv. Mater. 2016, 28, 5619.

[4] A. de Camargo, M. A. B. Regitano-d'Arce, C. Telles Biasoto, F. Shahidi, Food Chem. 2016, 212, 395 .

[5] R. Deprez-Poulain, N. Hennuyer, D. Bosc, W. G. Liang, E. Enée, X. Marechal, J. Charton, J. Totobenazara, G. Berte, J. Jahklal, T. Verdelet, J. Dumont, S.

Dassonneville, E. Woitrain, M. Gauriot, C. Paquet, I. Duplan, P. Hermant, F.-X. Cantrelle, E. Sevin, M. Culot, V. Landry, A. Herledan, C. Piveteau, G. Lippens, F. Leroux, W.-J. Tang, P. van Endert, B. Staels, B. Deprez, Nat. Commun. 2015, 6, 8250.

[6] U. Krauss, T. Drepper, K. E. Jaeger, Chem. - A Eur. J. 2011, 17, 2552. 


\section{WILEY-VCH}

[7] J. S. Donner, S. A. Thompson, C. Alonso-Ortega, J. Morales, L. G. Rico, S. I. C. O. Santos, R. Quidant, ACS Nano 2013, 7, 8666.

[8] X.-M. Zhu, C. Fang, H. Jia, Y. Huang, C. H. K. Cheng, C.-H. Ko, Z. Chen, J. Wang, Y.-X. J. Wang, Nanoscale 2014, 6, 11462.

[9] S. Paterson, S. A. Thompson, J. Gracie, A. W. Wark, R. de la Rica, Chem. Sci. 2016, 7, 6232.

[10] G. Baffou, C. Girard, R. Quidant, Phys. Rev. Lett. 2010, 104, 136805.

[11] S. Maity, W.-C. Wu, C. Xu, J. B. Tracy, K. Gundogdu, J. R. Bochinski, L. I. Clarke, Nanoscale 2014, 6, 15236.

[12] A. McLintock, C. A. Cunha-Matos, M. Zagnoni, O. R. Millington, A. W. Wark, ACS Nano 2014, 8, 8600.

[13] M. F. Tsai, S. H. G. Chang, F. Y. Cheng, V. Shanmugam, Y. S. Cheng, C. H. Su, C. S. Yeh, ACS Nano 2013, 7, 5330.

[14] N. Aissaoui, L. Bergaoui, S. Boujday, J. F. Lambert, C. Methivier, J. Landoulsi, Langmuir 2014, 30, 4066.

[15] M. González, C. E. Argaraña, G. D. Fidelio, Biomol. Eng. 1999, 16, 67.

[16] R. M. Pallares, S. L. Kong, T. Hui Ru, N. T. K. Thanh, Y. Lu, X. Su, Chem. Commun. 2015, 14524.

[17] O. I. Wilner, Y. Weizmann, R. Gill, O. Lioubashevski, R. Freeman, I. Willner, Nat. Nanotechnol. 2009, 4, 249.

[18] S. E. Lohse, C. J. Murphy, 2013.

[19] H. H. Richardson, M. T. Carlson, P. J. Tandler, P. Hernandez, A. O. Govorov, Nano Lett. 2009, 9, 1139.

[20] Z. J. Weng, M. Hendrickx, G. Maesmans, K. Gebruers, P. Tobback, J.Food Sci. 1991, $56,574$.

[21] J. Chen, D. Wang, J. Xi, L. Au, A. Siekkinen, A. Warsen, Z. Y. Li, H. Zhang, Y. Xia, 


\section{WILEY-VCH}

X. Li, Nano Lett. 2007, 7, 1318.

[22] C. Loo, A. Lowery, N. Halas, J. West, R. Drezek, Nano Lett. 2005, 5, 709.

[23] A. M. Gobin, M. H. Lee, N. J. Halas, W. D. James, R. A. Drezek, J. L. West, Nano Lett. 2007, 7, 1929.

[24] L. Freage, A. Trifonov, R. Tel-Vered, E. Golub, F. Wang, J. S. McCaskill, I. Willner, Chem. Sci. 2015, 6, 3544.

[25] A. Küchler, M. Yoshimoto, S. Luginbühl, F. Mavelli, P. Walde, Nat. Nanotechnol. 2016, 11, 409.

[26] S. Boye, F. Ennen, L. Scharfenberg, D. Appelhans, L. Nilsson, A. Lederer, Macromolecules 2015, 48, 4607. 


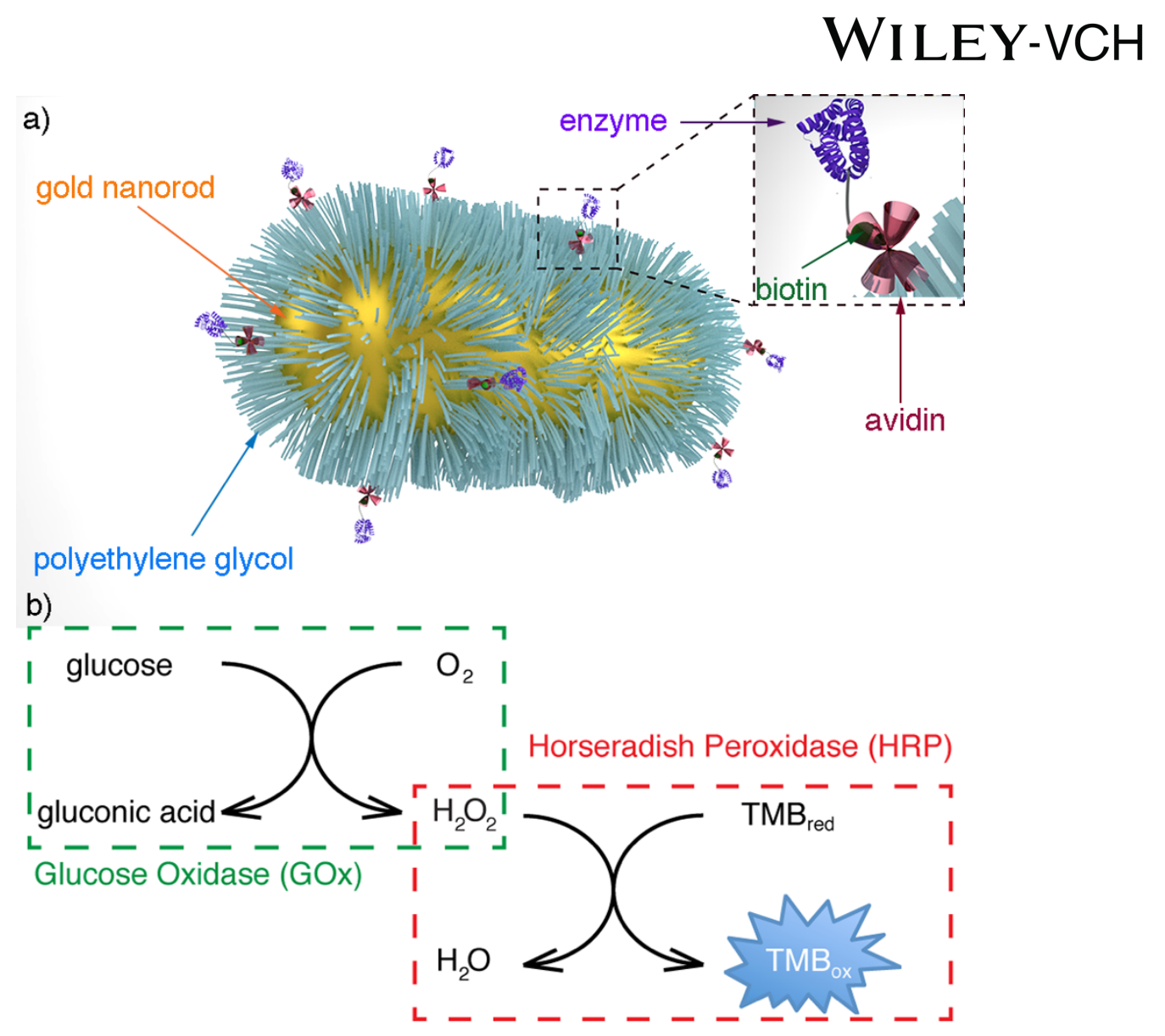

Figure 1. a) Schematic representation of the nanoparticle design used here to inactivate enzymes with light. Gold nanorods covered with polyethylene glycol (PEG) were covalently modified with the thermostable protein avidin; this allowed immobilizing biotinylated enzymes (horseradish peroxidase or glucose oxidase) a few nanometers away from the nanorods, where the temperature generated by the nanoheaters is the highest upon irradiation with a NIR laser. ${ }^{[11]}$ b) Scheme showing the enzyme cascade comprising glucose oxidase (GOx) and horseradish peroxidase (HRP). TMB: 3,3',5,5'-tetramethylbenzidine. 
WILEY-VCH
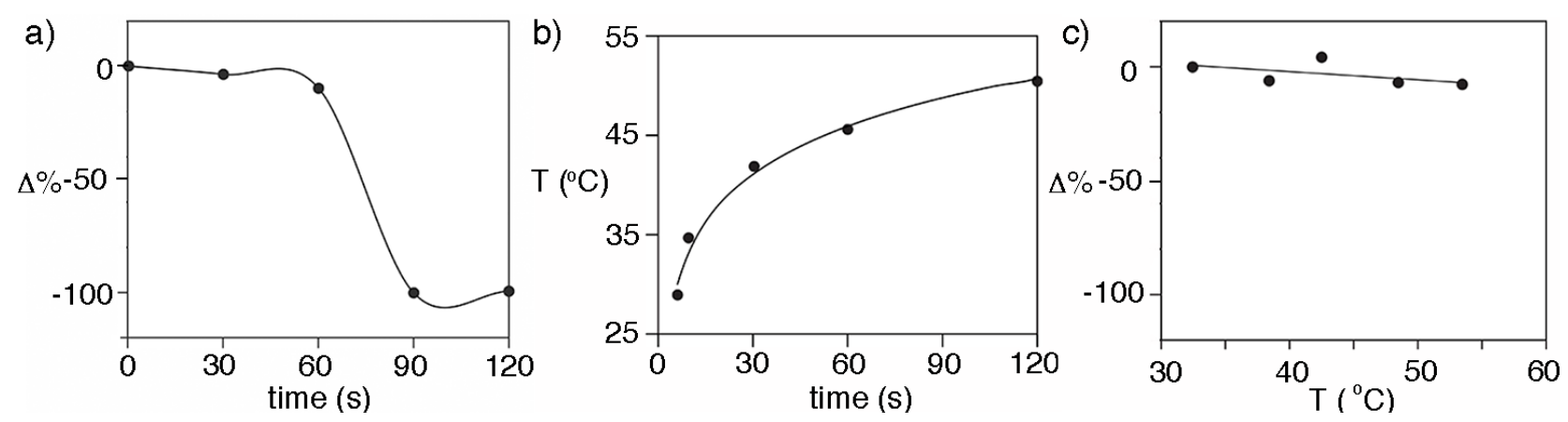

Figure 2. Photothermal inactivation of enzymes via local generation of plasmonic heat. a)

Percentage decrease in HRP activity measured after irradiating HRP-bound nanorods for different times. b) Increase in the temperature of the solution triggered by the irradiation of the nanorods. c) Percentage decrease in HRP activity measured after holding the temperature of the solution at different final values for $120 \mathrm{~s}$.
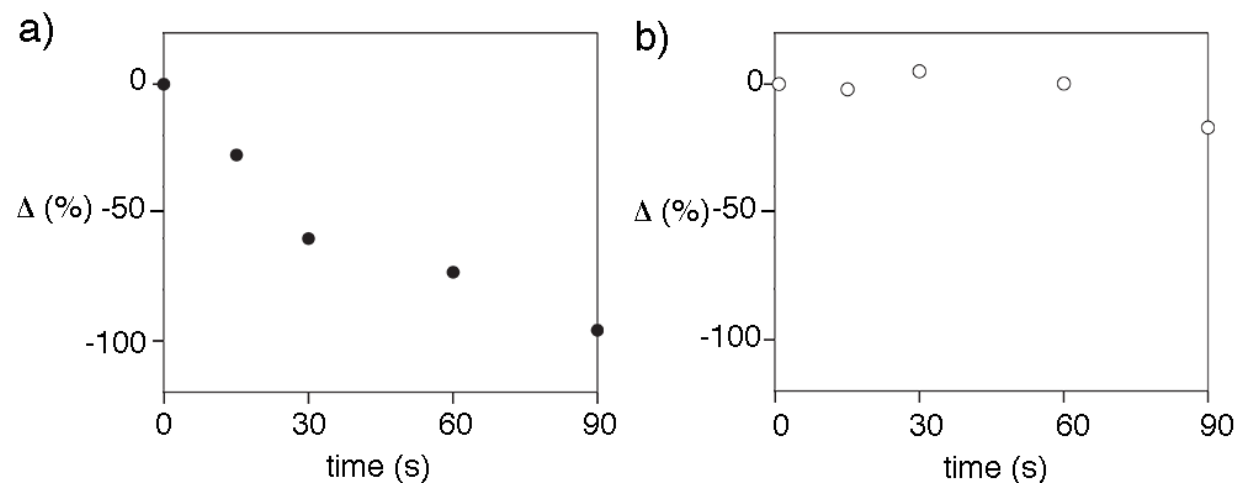

Figure 3. Variation of enzyme activity triggered by different irradiation times in an enzyme cascade containing nanorod-bound GOx and free HRP. a) Activity of the enzyme cascade measured upon addition of glucose; under this condition the measured activity is intimately related to the GOx activity, which generates hydrogen peroxide via glucose oxidation. b) HRP activity was measured upon addition of hydrogen peroxide not glucose; under this condition the measured HRP activity is independent from the GOx activity. 


\section{WILEY-VCH}

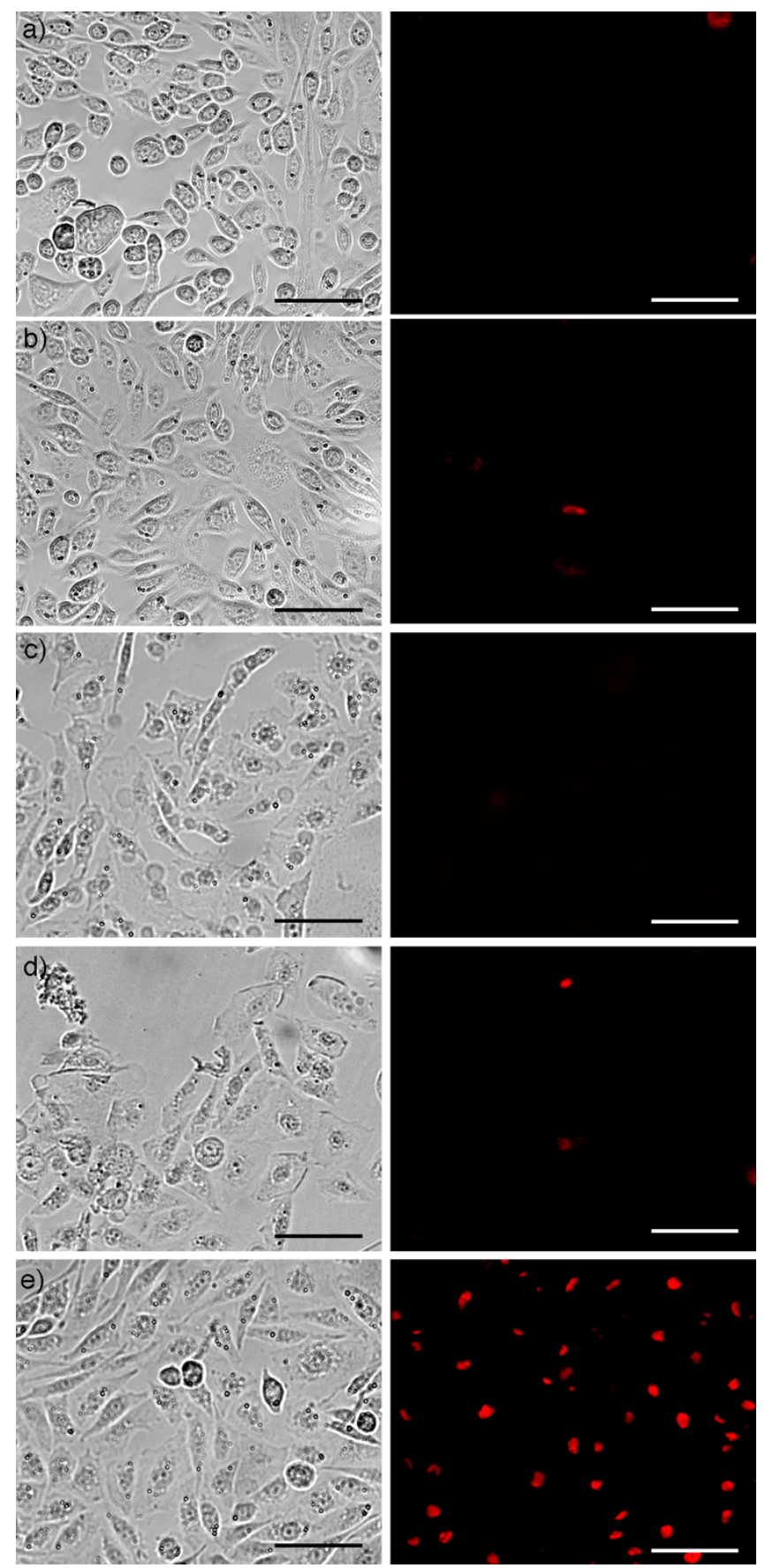

Figure 4. Bright-field microscopy (left) and fluorescence microscopy (right) images of CHO cells incubated with gold nanorods after irradiation with a $785 \mathrm{~nm}$ laser for a) $15 \mathrm{~s}$; b) $30 \mathrm{~s}$; c) $60 \mathrm{~s}$; d) $90 \mathrm{~s}$; e) $600 \mathrm{~s}$. Cells were incubated with ethidium bromide, which only stains the nuclei of cells whose membrane has been damaged. Scale bars: $100 \mu \mathrm{m}$. 


\section{WILEY-VCH}

A universal method for inactivating enzymes on demand is introduced, which involves irradiating nanorod-bound enzymes with near-infrared light. The subsequent generation of plasmonic heat denatures the enzymes selectively without damaging other proteins or cell membranes present in the same solution.

\section{Nanoheaters}

Sebastian A. Thompson, Sureyya Paterson, Marwa M. M. Azab, Alastair W. Wark, and Roberto de la Rica.*

\section{Light-Triggered Inactivation of Enzymes with Photothermal Nanoheaters}

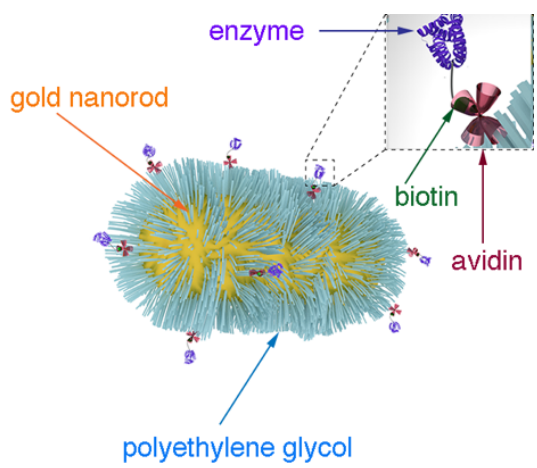




\section{WILEY-VCH}

Copyright WILEY-VCH Verlag GmbH \& Co. KGaA, 69469 Weinheim, Germany, 2013.

\section{Supporting Information}

\section{Light-Triggered Inactivation of Enzymes with Photothermal Nanoheaters}

Sebastian A. Thompson, Sureyya Paterson, Marwa M. M. Azab, Alastair W. Wark, and Roberto de la Rica.*

\section{Experimental Section.}

\section{Synthesis of gold nanorods}

Nanorod solutions were prepared via a modified seed-based procedure developed by Sau and Murphy ${ }^{(1)}$ and Nikoobakht and El-Sayed, ${ }^{(2)}$ and scaled up to $500 \mathrm{~mL} .^{(3)}$

Preparation of Seed Solution: A cetyltrimethylammonium bromide (CTAB) solution ( $5 \mathrm{~mL}$, $0.2 \mathrm{M})$ was mixed with $\mathrm{HAuCl}_{4}(5 \mathrm{ml}, 0.82 \mathrm{mM})$ under stirring, to which freshly prepared $\mathrm{NaBH}_{4}(0.65 \mathrm{~mL}, 0.012 \mathrm{M})$ was added, giving a brownish-yellow solution kept at $25{ }^{\circ} \mathrm{C}$ and used at once.

Growth Solution: First, a $\mathrm{AgNO}_{3}$ solution $(10 \mathrm{~mL}, 7.3 \mathrm{mg})$ was added to CTAB $(200 \mathrm{~mL}, 0.2$ M). Then, $\mathrm{HAuCl}_{4}(200 \mathrm{ml}, 1.0 \mathrm{mM})$ was added and the solution gently mixed by inversion. Ascorbic acid $(2.8 \mathrm{~mL}, 0.08 \mathrm{M})$ was then added producing a colour change from orange to colourless. Freshly prepared seed solution $(250 \mu \mathrm{L})$ was added to the growth solution and kept in a water bath at $37^{\circ} \mathrm{C}$ for $48 \mathrm{hrs}$. The solution was then centrifuged at $8000 \mathrm{rpm}$ for 1 hour and re-suspended in $1 \mathrm{mM} \mathrm{CTAB}$ to a final volume of $50 \mathrm{~mL}$. This last step was repeated 2 additional times and the resulting nanorod dispersion stored in the water bath until use.

\section{Modification of gold nanorods with avidin}

$20 \mathrm{~mL}$ of nanorods with an optical density at $785 \mathrm{~nm}$ of 1.0 were centrifuged at $13,000 \mathrm{rpm}$ for 


\section{WILEY-VCH}

$15 \mathrm{~min}$. The solution was removed and the pellets were collected in a single tube. Polyethylene glycol (PEG) with thiol and carboxylate ends (MW: $5 \mathrm{kDa}$ ) was then added to a final concentration of ca. $0.1 \mathrm{mM}$. The nanorod dispersion was then sonicated for $30 \mathrm{~min}$ followed by overnight incubation at room temperature to facilitate ligand exchange. Then excess ligands and surfactants were removed via centrifugation at $13,000 \mathrm{rpm}$ for 15 minutes followed by dissolution of the resulting pellet in $1 \mathrm{~mL}$ of Milli-Q water. This process was performed at least 3 times. Then the carboxylate groups on the PEG ligands were transformed into sulfo-NHS esters via addition of N-(3-Dimethylaminopropyl)-N-ethylcarbodiimide hydrochloride (EDC, Sigma, $0.1 \mathrm{M}$ ) and $N$-Hydroxysulfosuccinimide (sulfo-NHS, Sigma, $0.1 \mathrm{M}$ ) in MES buffer (0.5 $\mathrm{M}, \mathrm{pH}$ 5.5). After $30 \mathrm{~min}$ the nanorods were centrifuged at 13,000 rpm for $10 \mathrm{~min}$. The supernatant was then removed and the pellet was gently dissolved with $1 \mathrm{~mL}$ of a solution containing avidin ( $1 \mathrm{mg} / \mathrm{mL}$ in PBS buffer). Control nanorods were obtained by adding bovine serum albumin (BSA, $1 \mathrm{mg} / \mathrm{mL}$ ) to the nanorods. After overnight incubation at $4{ }^{\circ} \mathrm{C}$, glycine $(0.1 \mathrm{M})$ was added for $30 \mathrm{~min}$ to cap any unreacted sulfo-NHS esters. Then the nanorods were washed 3 times by centrifugation $(10,000 \mathrm{rpm}, 10 \mathrm{~min})$ and kept in the fridge at $4{ }^{\circ} \mathrm{C}$ until used. To prove that avidin was covalently bound to the nanorods, biotin-HRP $(10 \mu \mathrm{g} / \mathrm{mL})$ was added to $50 \mu \mathrm{L}$ of nanorods modified with avidin or BSA for $30 \mathrm{~min}$ followed by washing by centrifugation 3 times. The HRP activity was measured as described in section 3 below. In Figure S2, the HRP activity is much higher in samples containing avidin-nanorods than in samples containing BSA-nanorods. This demonstrates that the biotin-HRP was bound to the avidin nanorods via specific biotin-avidin interactions, and therefore that the methodology for covalently binding avidin was successful.

\section{Modification of gold nanorods with enzymes}

Biotinylated enzymes were obtained using a biotinylation kit (EZ-link NHS-PEO4- 


\section{WILEY-VCH}

Biotinylation kit, Thermo Scientific). $10 \mu \mathrm{L}$ of biotinylated enzyme (1 mg/mL) was added to $100 \mu \mathrm{L}$ of the nanorod solution for $60 \mathrm{~min}$ followed by centrifugation at $10,000 \mathrm{rpm}$ for $10 \mathrm{~min}$ at 15 degrees and re-suspension in PBS, 3 times. Experiments in Figs $2 \mathrm{a}$ and 2c, and experiments in Figs. 3a and 3b were performed with enzyme-modified nanorods from the same batch in order to ensure that the concentration of nanorods and nanorod-bound enzymes was exactly the same in all experiments. The concentration of enzymes is intimately related to the concentration of avidin via high-affinity biotin-avidin interactions. Each nanorod can be considered as a cylinder of $40 \mathrm{~nm}$ height and $5 \mathrm{~nm}$ radius, and therefore with a surface area of $1413 \mathrm{~nm}^{2}$. Each avidin molecule can be considered as a sphere with a hydrodynamic radius of ca. $3 \mathrm{~nm} \cdot{ }^{[26]}$ This means that the highest surface coverage of avidin possible is 50 molecules per nanorod. Since the concentration of nanorods is $2 \mathrm{nM}$, and considering that there are between 1 and 50 molecules of avidin per nanorod, the concentration of GOx in the solution is between 2 and $100 \mathrm{nM}$.

\section{Photothermal inactivation of enzymes}

$20 \mu \mathrm{L}$ of the nanorod sample (concentration ca. $2 \mathrm{nM}$ ) was irradiated with a CW laser $(785 \mathrm{~nm}$ excitation wavelength, $235 \mathrm{~mW}$ at the point of incidence). The laser was focused into the sample with a $50 \mathrm{~cm}$ focal length PCX lens. The temperature in the drop was measured with a thermocouple (Digital Meter, model 6802 II).

\section{Measurement of enzyme activity}

HRP activity in Figure 2 was measured by recording the change in absorbance at $652 \mathrm{~nm}$ with time after addition of the enzyme substrate TMB in the presence of hydrogen peroxide (TMB substrate kit, commercially available from Thermo Scientific and prepared following the recommendations of the manufacturer). The TMB substrate was added to the nanorod solution 


\section{WILEY-VCH}

after photothermal (Fig. 2a) or thermal (Fig. 2c) treatment. All solutions contained the same concentration of enzyme-modified nanorods, and therefore the same concentration of HRP. The variation of absorbance with time resulting from the oxidation of TMB was measured with a

Cary 5000 spectrophotometer (see for example Fig. S2). The enzyme activity was calculated as the slope of the resulting curve in the region where it varies linearly with time. Variations in the activity of nanorod-bound enzymes were always calculated with respected to the sample corresponding to $t=0 \mathrm{~s}$. Therefore changes in the enzyme activity were always related to the photothermal or thermal treatment of the sample, and not to the immobilization of the enzymes on the nanorods. Changes in the enzyme activity are expressed as a percentage variation with respect to the $\mathrm{t}=0 \mathrm{~s}$ sample, which contains the same molar concentration of enzymes and nanorods $(\Delta \%$ in Figures 2 and 3$)$. Under these conditions $\Delta \%$ is not affected by the concentration of tethered enzyme.

In Figure 3a, samples containing nanorod-bound GOx and free HRP $(10 \mu \mathrm{g} / \mathrm{mL})$ were irradiated with the laser for different times as stated above. All solutions contained the same concentration of nanorods, and therefore the same concentration of GOx. A TMB solution was freshly prepared in DMSO $(1 \mathrm{~mL}, 1 \mathrm{mg} / \mathrm{mL})$. The solution was then diluted 10 times with citrate buffer (0.1 M, pH 6) containing 0.1 M glucose. The oxidation of TMB by HRP using the hydrogen peroxide generated by GOx in the presence of $0.1 \mathrm{M}$ glucose was triggered by adding $1 \mathrm{~mL}$ of the TMB and glucose solution to the solution containing GOx-nanorods and free HRP. Experiments in Figure $3 \mathrm{~b}$ were performed in the same conditions (same concentration of nanorods, GOx and HRP) but the HRP was measured by adding a TMB solution containing hydrogen peroxide not glucose (TMB substrate kit, commercially available from Thermo Scientific and prepared following the recommendations of the manufacturer). Variations in the activity of nanorod-bound enzymes were always calculated with respected to the same sample before illumination $(\mathrm{t}=0)$. 


\section{WILEY-VCH}

\section{Cell culture}

Prostatic small cell carcinoma (PC3) and Chinese hamster ovarian $(\mathrm{CHO})$ cells were kindly gifted from Professor Duncan Graham at the department of Pure and Applied Chemistry, University of Strathclyde, UK. They were grown in Dulbecco's modified Eagle's medium supplemented with $10 \%$ Fetal Bovine Serum (FBS). Cells were maintained at $37^{\circ} \mathrm{C}$ in a $5 \%$ $\mathrm{CO}_{2}$ humidified environment. Two days before the photothermal experiments, cells were trypsinized, centrifuged and plated onto $35 \mathrm{~mm}$ petri dish in complete cell growth medium. Cell confluence was between 70 and $85 \%$ the day of the experiment. Complete cell growth medium was replaced with $1 \mathrm{~mL}$ PBS containing the enzyme-modified nanorods with a concentration of ca. $1 \mathrm{nM}$. Irradiation of the samples was performed immediately after (within 2 minutes) as previously described. Nanorod uptake and interactions with the plasma membrane are considered minimal under these conditions. ${ }^{4}$

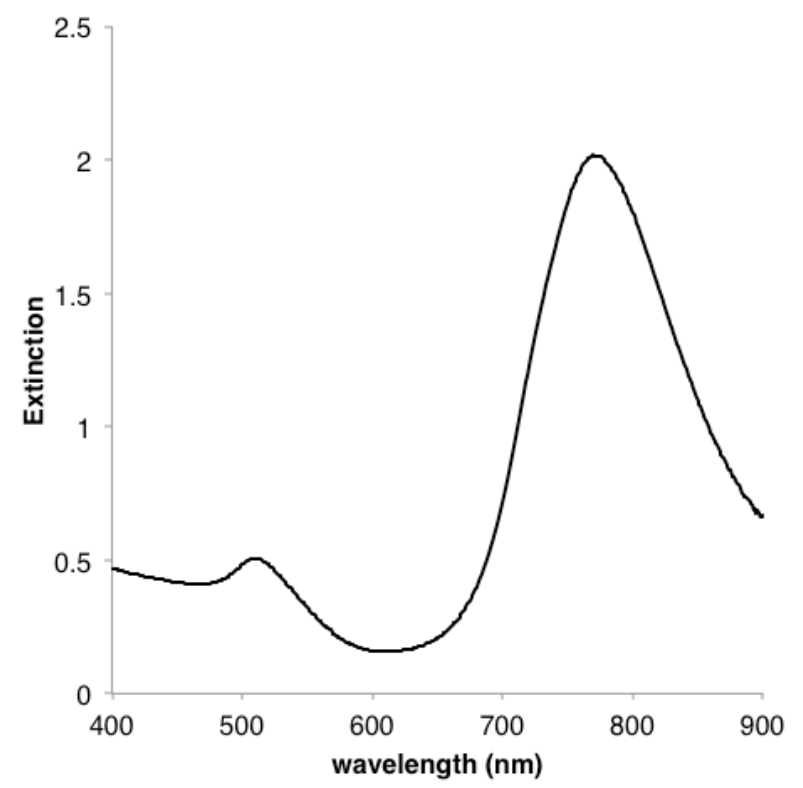

Figure S1. Extinction spectrum of the gold nanorods. 


\section{WILEY-VCH}

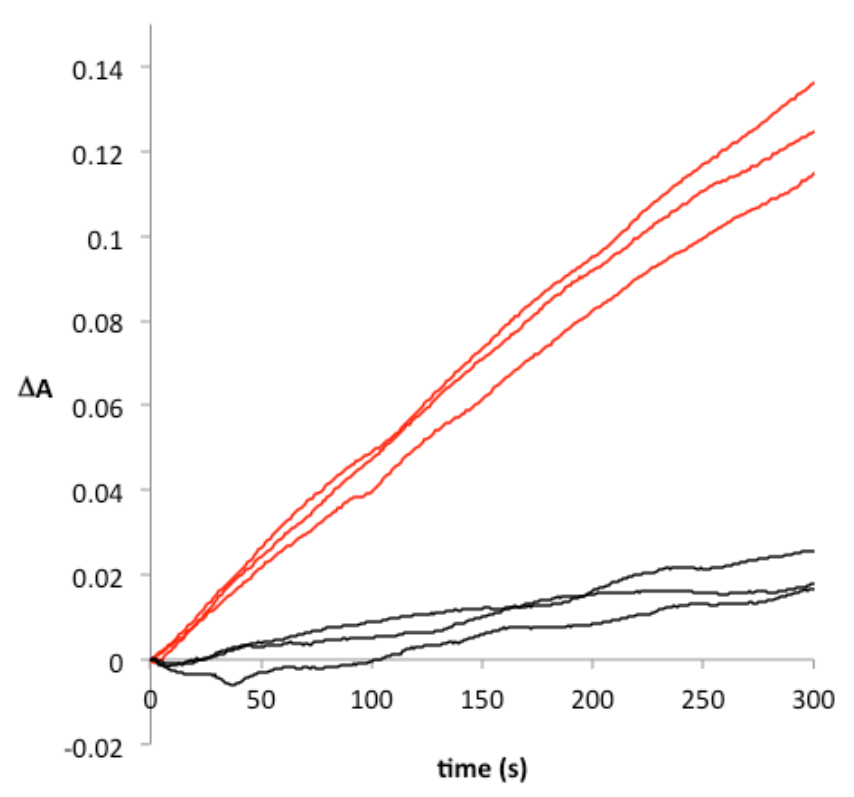

Figure S2. HRP activity measured after incubating nanorods modified with either avidin (red) or BSA (black) with biotin-HRP for 30 min followed by removal of excess enzymes and addition of the TMB substrate. The HRP activity is higher in nanorods modified with avidin, which demonstrates that the covalent binding of avidin to nanorods was successful. These experiments also prove that HRP remains active after binding the nanorods.

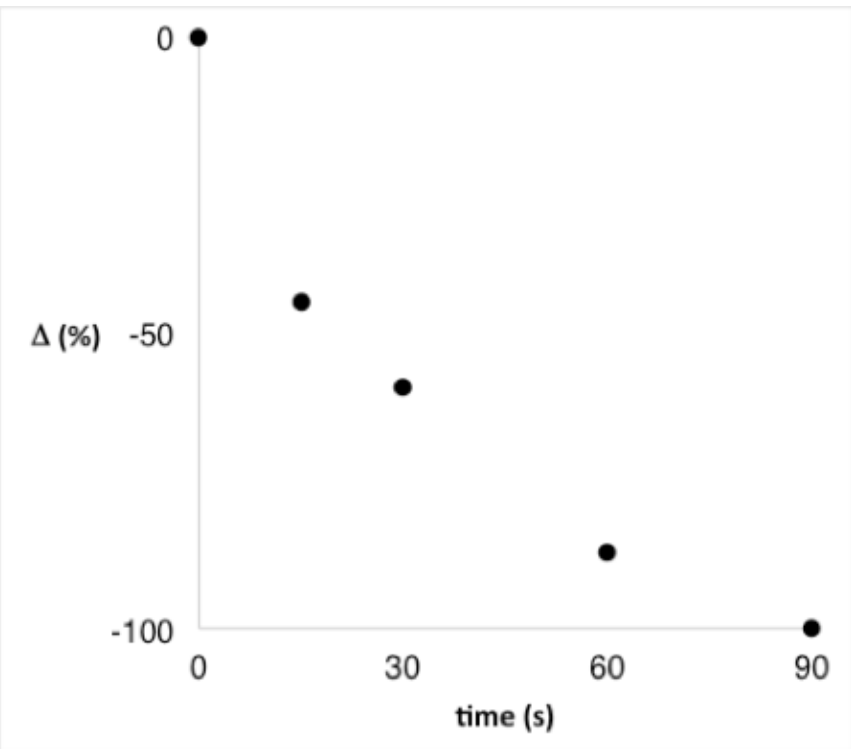

Figure S3. Photothermal inactivation of nanorod-bound GOx in the presence of CHO cells as a function of the irradiation time. 


\section{WILEY-VCH}
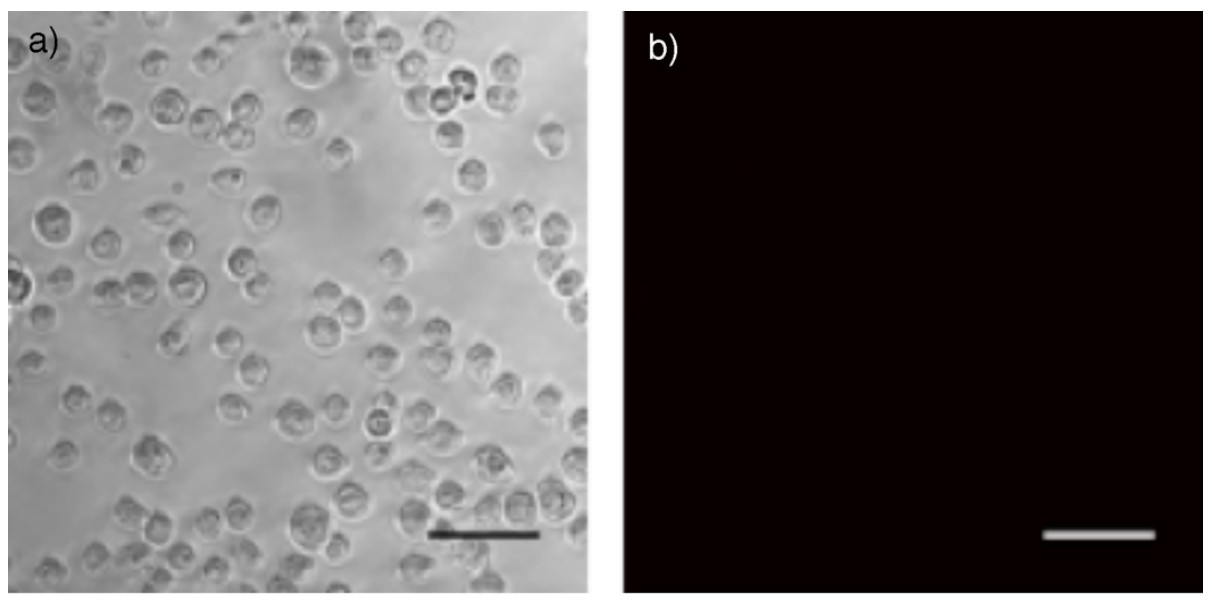

Figure S4. Bright-field microscopy (a) and fluorescence microscopy (b) images of CHO cells after irradiation with a $785 \mathrm{~nm}$ laser for $600 \mathrm{~s}$ in the absence of gold nanorods. Cells were incubated with ethidium bromide, which only stains the nuclei of cells whose membrane has been damaged. Scale bars: $100 \mu \mathrm{m}$.

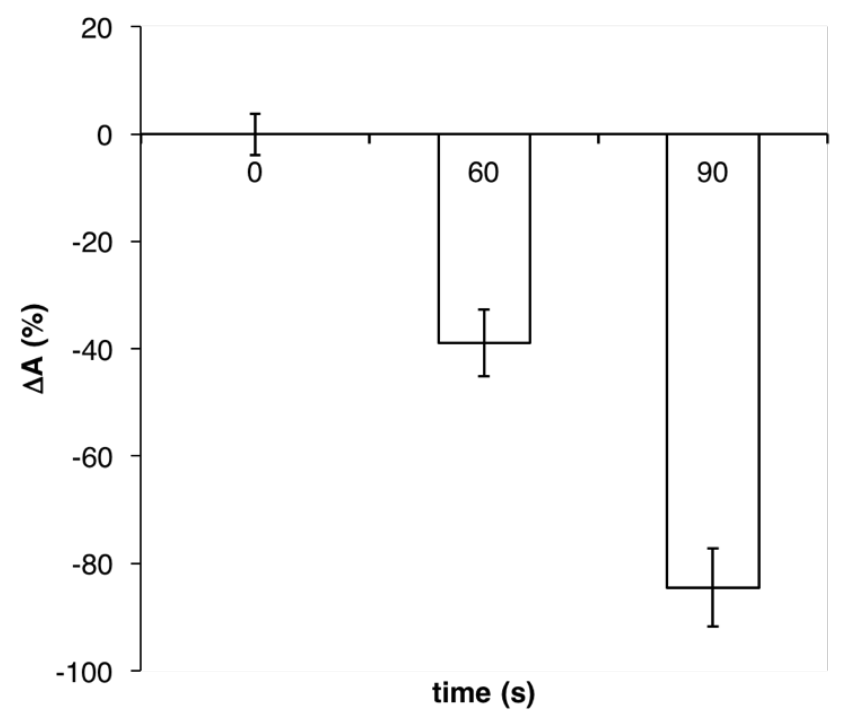

Figure S5. Photothermal inactivation of nanorod-bound HRP after 0,60 or $90 \mathrm{~s}$ irradiation time. Error bars are the standard deviation from 3 independent experiments.

\section{References}




\section{WILEY-VCH}

(1) Sau, T. K.; Murphy, C. J. Seeded High Yield Synthesis of Short Au Nanorods in Aqueous Solution. Langmuir 2004, 20, 6414-6420.

(2) Nikoobakht, B.; El-Sayed, M. A. Preparation and Growth Mechanism of Gold Nanorods (NRs) Using Seed-Mediated Growth Method. Chem. Mater. 2003, 15, 1957-1962.

(3) Alison McLintock, Carlota A. Cunha-Matos, Michele Zagnonic, Owain R. Millingtond and Alastair W. Wark, Universal Surface-Enhanced Raman Tags: Individual Nanorods for Measurements from the Visible to the Infrared (514 - $1064 \mathrm{~nm})$. ACS Nano, 2014, $8,8600-8609$.

(4) Jon S. Donner, Sebastian A. Thompson, Mark P. Kreuzer, Guillaume Baffou, and Romain Quidant. Mapping Intracellular Temperature Using Green Fluorescent Protein. Nano Lett., 2012, 12 (4), pp 2107-2111 